\title{
Malondialdehyde (MDA) as a Marker of Platelet Function in Rats with CCI4-Induced Toxic Hepatopathy
}

\author{
ROXANA IRINA IANCU ${ }^{1,2}$, PAULA MIHAELA TOADER ${ }^{1,3 *}$, MADALINA MOCANU ${ }^{1,3 *}$, \\ CAMIL CIPRIAN MIRESTEAN ${ }^{4,5}$, DRAGOS IANCU ${ }^{1,6}$ \\ ${ }^{1}$ „Grigore T.Popa” University of Medicine and Pharmacy, 16 Universitatii Str., 700115, Iasi, Romania \\ ${ }^{2}$ „St. Spiridon” Universitary Emergency Hospital Iasi, 1 Independentei, 700111, Iasi, Romania \\ ${ }^{3}$ University Clinical Hospital C.F. Iasi, 1 Garabet Ibraileanu Str., 700506, Iasi, Romania \\ ${ }^{4}$ EUROCLINIC Oncological Center, Iasi, 2 Vasile Conta Str., 700106, Iasi, Romania \\ ${ }^{5}$ University of Medicine and Pharmacy Craiova, 2 Petru Rares Str., 200349, Craiova, Romania \\ ${ }^{6}$ Regional Institute of Oncology Iasi, 2-4 Henry Mathias Berthelot, 700483, Iasi, Romania
}

\begin{abstract}
Blood platelets are pivotal cells in the process of hemostasis and thrombosis. In the majority of patients with severe liver disease, platelet function appeared defective. We determinate platelet adhesiveness, aggregability and MDA level, in rats with acute and chronic hepatopathy induced by CCl4 administration. Our data relieves that platelet functions are not only affected in chronic toxic affectation, but also in acute intoxication ( $p<0.05)$. Icosanoids production (expressed in MDA levels) are significantly decreased only in chronic CCl4 intoxication $(p<0.001)$. Significant correlation appears between aggregability and MDA $(r=-$ $0.78)$ and adhesiveness and MDA $(r=-0.57)$ in group $C$, with chronic CCl4 intoxication. The complexity of these platelet functions related to the hepatic disease is still a matter of debate and needs further investigation.
\end{abstract}

Keywords: malondyaldehyde (MDA), platelets, liver, lipid peroxidation

\section{Introduction}

Liver is considered a hematopoietic organ in the fetal period, while thrombopoietin is being produced by mature hepatocytes. Thrombocytopenia is a well-known characteristic of chronic liver diseases, but in addition to the quantitative changes in platelets, there are other qualitative defects $[1,2,3]$. The gold standard for platelet function assessment is the aggregometry (optical light turbidity is a measure of aggregation after stimulation to different sets of agonis), which is tremendously helpful in detecting the bleeding tendency during preoperative period [4-7].

Human platelets are known to a main source of MDA formation in human blood [8]. Therefore, platelet function and activity are closely related to the composition of the phospholipid membrane (account for $65 \%$ of all platelet lipids) [9]. MDA formation parallels the generation of TxA-2, a potent agonist for platelet aggregation.

Carbon tetrachloride (CCl4) is a widely used chemical for experimental induction of fatty liver and liver fibrosis in animals [10]. Its biotransformation produces hepatotoxic metabolites, the highly reactive trichloromethyl-free radical, subsequently converted to the peroxytrichloromethyl radical [11-12]. Additionally, the decomposition of lipid hydroperoxides leads to a variety of final products, one of which is malondialdehyde (MDA), a typical aldehydic product of lipid peroxidation. In platelets, the thromboxane synthase enzyme catalyzes the conversion of PGH2 to both thromboxane A2 and malondialdehyde (MDA) in approximately equimolar amounts.

The aim of our study was to evaluate MDA production in platelets as a marker of platelet function in correlation with platelet adhesiveness and platelet aggregability.

\section{Materials and methods}

\section{Chemicals}

CCl4, ADP, TRIS, Triton $-\mathrm{X}, 1$ 1.1.3.3 Tetramethoxypropan, thiobarbituric acid (TBA) and trichloroacetic acid have been produced by Sigma Chemical Company, Germany. All the other chemicals used were of the highest quality available on the market.

\footnotetext{
*email: toaderpaula@gmail.com,drmadalinamocanu@yahoo.com
} 


\section{Study design}

19 male Wistar rats, weighting $216-274 \mathrm{~g}$ were purchased from Cantacuzino Laboratory and randomly divided into 3 groups, each consisting of 6-7 animals. All animals were housed in an environmentally controlled

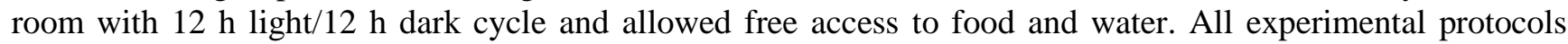
followed the criteria of University of Medicine and Pharmacy "Gr. T. Popa" Iasi for the care and use of laboratory animal's research. Group I (M-control) received mineral oil $(0.5 \mathrm{~mL}$, intra-peritoneal, $n=6)$ as normal control; group II (A-acute) received $\mathrm{CCl} 4(0.01 \mathrm{~mL} / \mathrm{kg}$ body weight in $0.5 \mathrm{~mL}$ mineral oil intra-peritoneal, single dose, $n=7)$, group III (C-chronic) received CCl4 $(0.08 \mathrm{~mL} / \mathrm{kg}$ body weight in $0.5 \mathrm{~mL}$ mineral oil i.p, $\mathrm{n}=$ 6.) twice per week for 8 weeks. Forty-eight hours after the last CCl4 injection, the animals were anaesthetized by sodium thiopental injection $(50 \mathrm{mg} / \mathrm{kg}$ ) and blood was collected from the rats via open chest cardiac puncture. The rats were then euthanatized, their livers were carefully dissected, weighed and cleaned of extraneous tissues and parts of the liver tissue were immediately transferred to $10 \%$ formalin for histopathological assessments.

\section{Preparing Platelet-Rich Plasma}

The blood was collected in vacutainers with sodium citrate $(3.8 \%, 9$ parts of blood to 1 part of sodium citrate as anticoagulant solution) to prevent blood clot [13]. Then the blood was centrifuged at $1000 \mathrm{rpm}$ for $15 \mathrm{~min}$ at $20^{\circ} \mathrm{C}$ for separation of platelet rich plasma.

Platelets MDA concentration was measured, after being stimulated by ADP $10 \mu \mathrm{M}$ following a method based on thiobarbituric acid (TBARS) reactivity [14]. After mixing trichloroacetic acid with the sample and centrifuging, a supernatant was obtained and TBA was added.
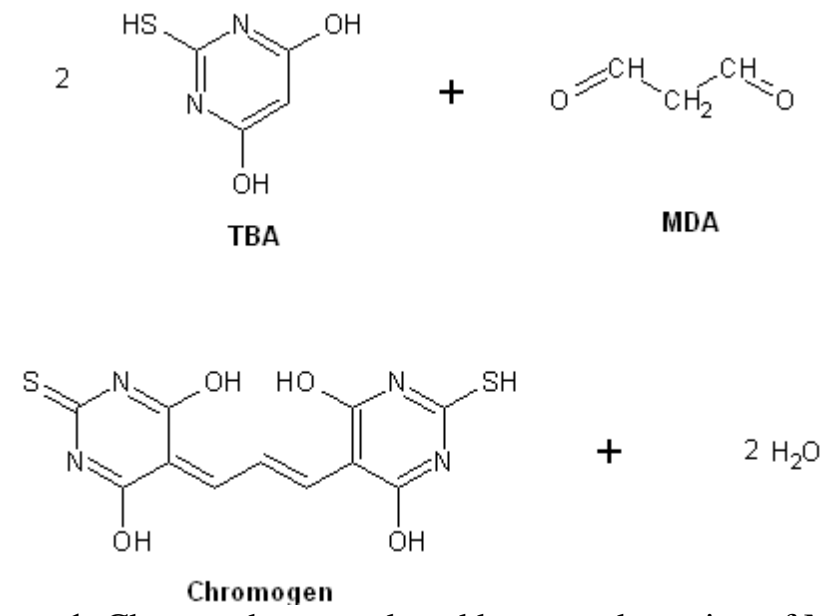

Figure 1. Chromophore produced by a condensation of MDA

with TBA adapted from

https://www.intechopen.com/media/chapter/38473/media/image3.png

The absorbance of the sample was measured at $532 \mathrm{~nm}$ with a spectrophotometer. MDA concentration was calculated according to the formula provided in the protocols.

Platelet adhesiveness and platelet aggregation have been determined also by using a TECAN SUNRISE microplate reader according to the methods described by P.Bellavitte in Analytical Biochemistry [15]., 1994 (adhesion) and Bednar et al. 1995, Throm Res (aggregation) to evaluate platelet functions [16].

Histopathological Studies. Hepatic tissue was processed by usual histopathological technique: $10 \%$ formalin fixed, paraffin embedded, Hematoxylin-Eosin and Van Gieson stained. The sections were studied for histopathological changes: necrosis, fatty changes, ballooning degeneration and inflammation. Histological damages scored as follows: 0: absent; +: mild; ++: moderate; and+++: severe.

Statistical analysis was performed by using the SPSS 17.0 statistical package. All results are expressed as mean \pm standard deviation (SD). Statistical significance of differences between groups was analyzed by using one-way ANOVA with an unpaired Student's t-test.

Correlations between continuous parameters were assessed by using Pearson's correlation analysis. Differences of $\mathrm{P}<0.05$ were considered statistically significant. 


\section{Results and discussions}

In order to assess the potential effect of $\mathrm{CCl} 4$ intoxication in inducing hepatomegaly, liver weight and liver weight in connection to body weight were determinated in both $\mathrm{A}$ and $\mathrm{C}$ groups vs. control group (M). Older studies reveal that the relation between liver weight and body weight was a more sensitive toxicity indicator than the simple liver weight [17]. Table 1 show values for liver weight and liver index (defined like body weight/ liver weight*100).

Table 1. Results and comparisons of Body weight (g), Liver weight (g) and Index liver in all groups

\begin{tabular}{|cccc|}
\hline & Group I (M) & Group II (A) & Group III (C) \\
& $\mathrm{n}=6$ & $\mathrm{n}=6$ & $275,66 \pm 23,09$ \\
\hline Body weight (g) & $242,8 \pm 12,86$ & $244 \pm 20,12$ & $9,66 \pm 1,50$ \\
Liver weight (g) & $9,2 \pm 0,98$ & $9,28 \pm 1,11$ & $3,78 \pm 0,27$ \\
Index liver (body weight/liver & $3,50 \pm 0,79$ & $3,80 \pm 0.37$ & Values as mean \pm S.D. \\
weight*100) & & & \\
\hline
\end{tabular}

No statistically significant differences were noted in relation to the acute and chronic CCl4 administration $v s$. control group, in accord with other several studies [18]. Body weight values are also noted in Table 1, but the changes of body weight under acute/chronic $\mathrm{CCl} 4$ administration was not one of the objectives of our study.

Histopathological studies revealed that $\mathrm{CCl} 4$ imposed focal necrosis, fatty changes, ballooning degeneration, hydropic degeneration, centrolobular venous stasis and the infiltration of lymphocytes around the central veins, mitosis (Figure 2) .

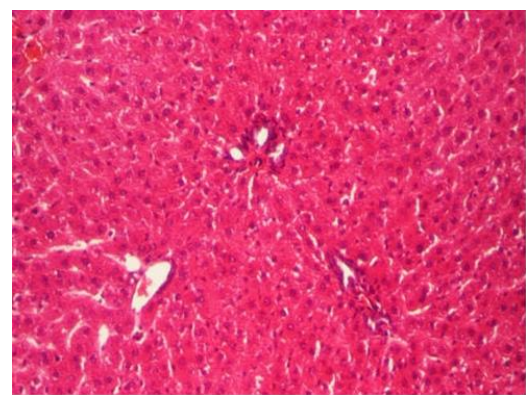

(a) M6 HE x 10. Liver with normal structure: centrolobular vein; hepatocytes with sinusoidal capillaries arranged in cords each arranged radial around centrilobular vein spaces porto-bile

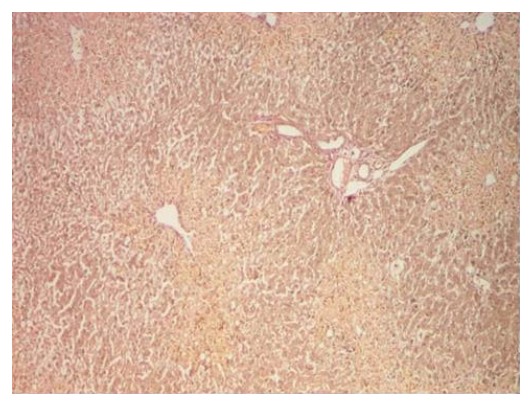

(b.) A5 VG x 4. Liver with preserved histological structure, hydropic degeneration, centrolobular venous stasis

Figure 2. Section of liver in control group (normal architecture) vs. CCl4 treated group

Preserved histological structure, hidropic degeneration and centrolobular venous stasis characterize acute lesion due to $\mathrm{CCl} 4$ administration (Figure 2). Necrosis, which is a more severe form of injury, was markedly present in pericentral hepatocytes to the vein and was associated with liver remodeled structure, regeneration node delimited by fibrosis bands; lipid cysts; aspects of hepatocyte regeneration, characteristic for liver cirrhosis in chronic CCl4 administration (Figure 3, 4). [19].

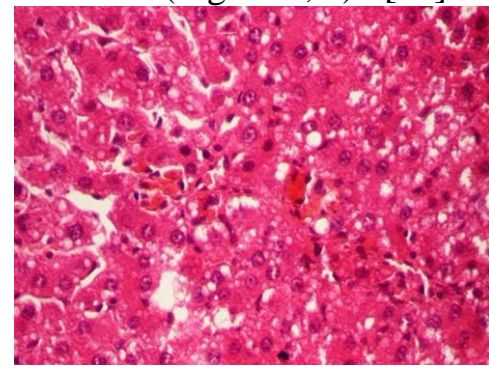

(c) A2 HE x 20 Liver with preserved structure, hemorrhagic hepatocytolisis perivenously centrilobular; hepatocyte hydropic degeneration, mitosis

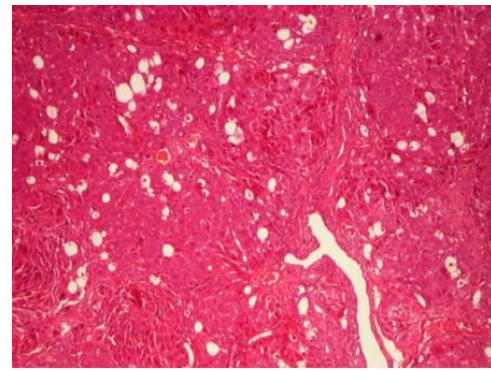

(d) C4 HE X 4, Liver cirrhosis: liver with remodeled structure, regeneration nodules delimited by fibrosis bands

Figure 3. Histopathological changes induced by acute $v$ s.chronic $\mathrm{CCl} 4$ in rat 
Van Gieson stain was used to highlight fibrosis. Experimental intraperitoneal administration of CCl4 model mimics toxic liver damage. If proinflammatory alterations are immediate, tissue harvesting after 24 and $48 \mathrm{~h}$ is recommended. Established fibrosis can be investigated after 2-4 weeks of CCl4 administration, while severe fibrosis (cirrhosis) can be observed after 6-8 weeks [20].

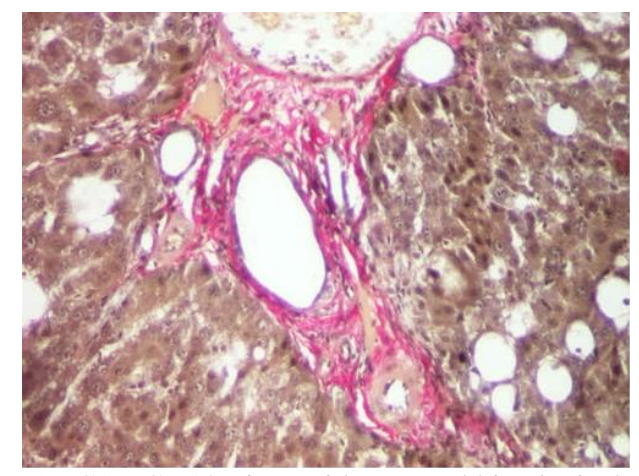

(e) C1 VG x10 Liver with resected histological structure, periportal fibrosis, macrovesicular steatosis and lipid cysts; aspects of hepatocyte regeneration; mitosis

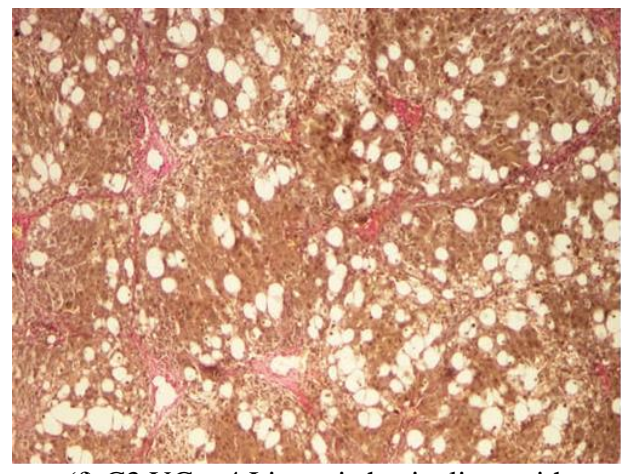

(f) C3 VG x 4 Liver cirrhosis: liver with

remodeled structure, regeneration node delimited by fibrosis bands; lipid cysts; aspects of hepatocyte regeneration

Figure 4. Histopathological changes induced by.chronic administration of $\mathrm{CCl} 4$ in rats

Different reports indicate that oxidative stress, specifically oxidative mitochondrial damage, can be responsible for hepatocyte damage apoptosis/necrosis in toxic hepatic diseases [21-23]. We monitored the prostaglandin pathway by measuring the production of malondialdehyde (MDA) induced by ADP. While the thiobarbituric acid reaction may be influenced by other lipid and non-lipid substances and hence is not completely specific for MDA, it has been suggested that only the MDA complex absorbs in the 450-550 nm range thus, so we used this region for the MDA measurements.

Results and comparisons of platelets MDA levels of the three groups were given in Figure 5 Normal platelets produced $9.07 \pm 2.11$ nmole of malondialdehyde $/ \mathrm{ml}$ in response to ADP $10 \mu \mathrm{M}$.

Malondialdehyde production was found to be decreased in $\mathrm{CCl} 4$ administered groups compared to control group ( $\mathrm{p}<0.001$ ), as we show in Figure 5. This pattern was observed with both concentrations of CCl4 administration.

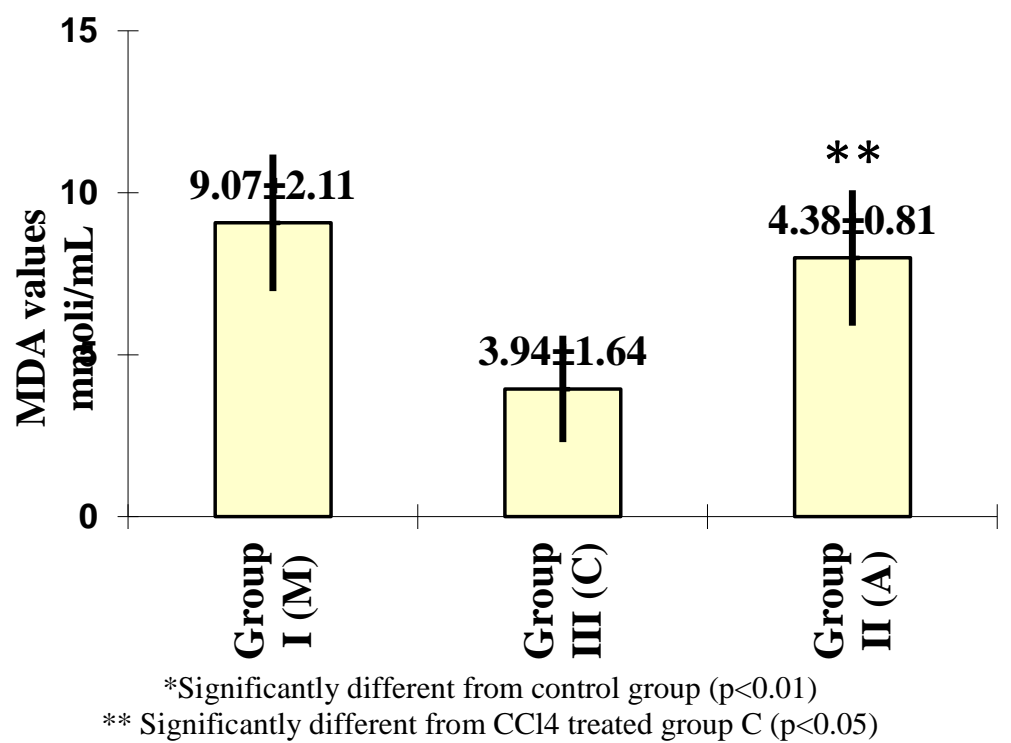

Figure 5. Effect on intraperitoneal $\mathrm{CCl} 4$ acute and chronic administration on MDA levels vs. control group

Platelet adhesiveness and platelet aggregation in response to ADP $10 \mu \mathrm{M}$ were also decisive in evaluating the platelet function in correlation with platelets MDA levels. Despite this heterogeneity in aggregation responses, our findings clearly indicate that ADP induced aggregation and platelet adhesiveness is abnormal in animals with acute and chronic $\mathrm{CCl} 4$ induced hepatopathy. 
The correlation of platelets MDA level with platelet adhesiveness and platelet aggregation in response to ADP $10 \mu \mathrm{M}$ was performed to identify which factors had relevance to MDA in in animals with acute and chronic $\mathrm{CCl} 4$ induced hepatopathy.

The plasma MDA level was not significantly correlated with the two factors stated above in control and acute $(\mathrm{r}=-0,32, \mathrm{r}=-0,02)$ and hepathopathy group $(\mathrm{r}=-0,06 ; \mathrm{r}=0.0,31)$, but only with data in chronic hepatopathy group ( $\mathrm{r}=-0,57, \mathrm{r}=-0,78$, respectively) (Figure 6), suggesting strong but negative relevance between them.

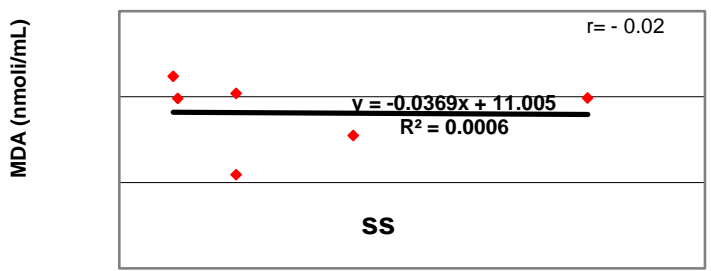

Adhesiveness (\%)

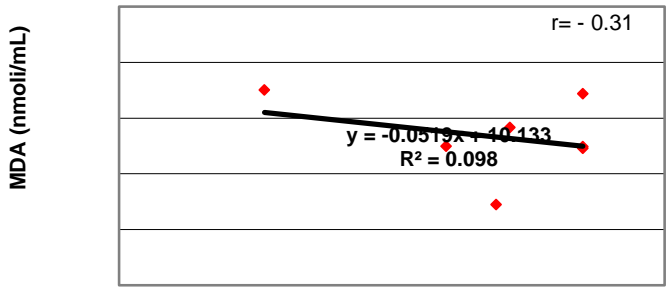

Adhesiveness (\%)

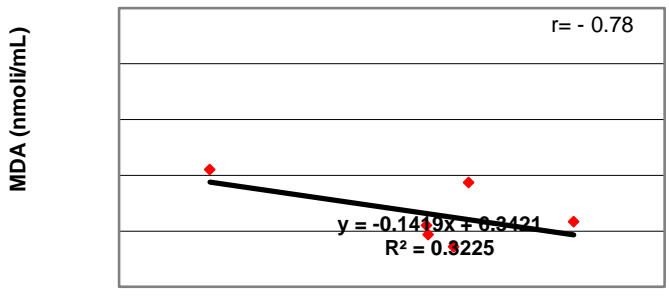

Adhesiveness (\%)

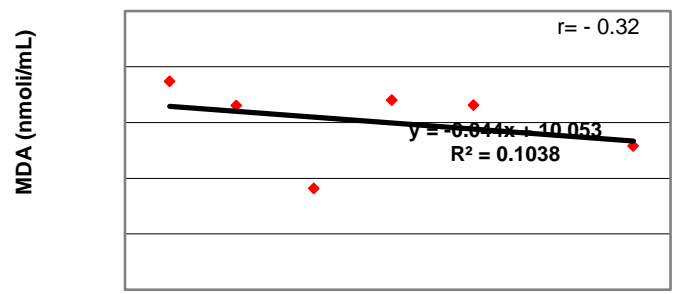

Aggregability (mOD/min)

a.

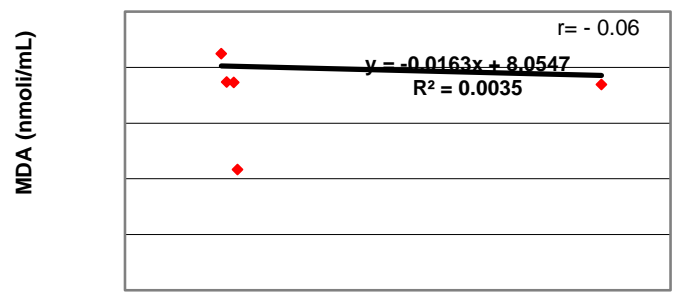

Aggregability (mOD/min)

b.

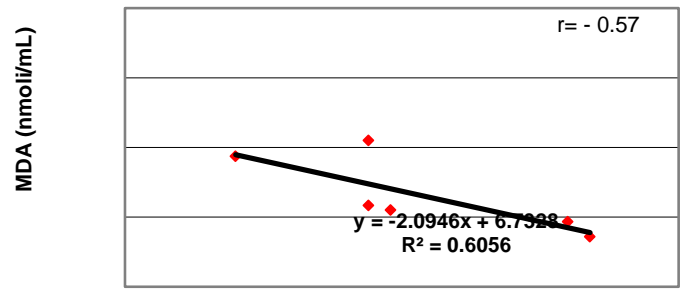

Aggregability (mOD/min)

c

Figure 6. Correlation of platelets MDA level with the platelet aggregation $(\mathrm{mOD} / \mathrm{min})$ and platelet adhesiveness (\%) in control group (a), acute hepathopaty group (b), chronic hepathopaty group (c).

Correlation between continuous parameters were assessed by using Pearson`s correlation

\section{Conclusions}

CCl4 administration in rats not only promotes the development of liver fibrosis, but also changes platelets activity presumably by lipid membrane modification. Platelet adhesiveness, platelet agreggability and platelet production of MDA are affected, but not in a necessarily correlated way.

Depressed activity of platelets and prostaglandin metabolism was strongly expressed in in chronic CCl4 hepatopathy group, perhaps by modifying the composition of the membrane phospholipids. Since platelet MDA is a byproduct of the PGG2 endoperoxide platelet, these results suggest that this phenomenon involves a decrease in platelet endoperoxide synthesis. 


\section{References}

1.MOCANU, M, BADESCU, M, LUPU, IC, BADULESCU, OV, Rev. Chim., 66(10), 2015, 1590-1593

2.MOCANU, M, BADESCU, M, HANCIANU, M, BADULESCU, OV, Rev. Chim., 66(7), 2015, 997-1000

3.MIFTODE, RS , MIFTODE, L, VATA, A, TRIFAN, A, COSTACHE, I, TOADER, S, et al. Medical Surgical Journal-Revista Medico-Chirurgicala, 2018, 122, Issue: 1 p. 51-58

4.GHEORGHEVICI T.S., VELICEASA B., PUHA B., TOADER S., ALEXA ID, ALEXA. O. Rev. Chim., 69(11), 2018, 4220-4224.

5.ALEXA O., PERTEA M., MALANCEA R.I., PUHA B., VELICEASA B., Rev. Med. Chir. Soc. Med. Nat., Iaşi 123(2):2019,p. 275-281.

6.PERTEA M, VELENCIUC N, GROSU O, VELICEASA B, POROCH V, LUNCA S. J Mind Med Sci. 5(2): 2018; p. 250-254

7.MALANCEA R.I., GAVRILIUC E.R., VELICEASA B., PUHA B., POPESCU D., ALEXA O. Mater. Plast. 54(3), 2017, 513-516

8.TSIKAS D, Anal Biochem, 524, 2017, p. 13-30

9.DOLEGOWSKA B, LUBKOWSKA A, DE GIROLAMO, J Biol Regul Homeost Agents, 26(2 Suppl. 1), 2012; p. 23S-33S

10.A. T. WILLIAMS, R. F. BURK, Seminars in Liver Disease, 10, no. 4, 1990, p. 279-284

11.VASINCU, D, IANCU, RI, CHELARU, L STOLERIU, G, COSTULEANU, M, Rev. Chim., 69 (6), 2018, 1570-1573

12.TATARCIUC, D, VASINCU, D, STOLERIU, G, IANCU, RI, COSTUlEANU, M, Rev. Chim., 69 (5), 2018, 1187-1190

13.DELIANU, C., FOIA, HURJUI, LL, VLAD, CE, TUCHILUS, C, TARNICERIU, CC, STOLNICEANU, CR, TOMA, CLINICAL LABORATORY, Volume: 65 Issue: 11, p. 2185-2191

14.BUEGE JA, AUST SD. Methods Enzymol. 52, 1978, p. 302-10.

15.BEDNAR B, CONTRA C, GOULD RJ, CONNOLLY TM., Throm Res 77, 1995, p. 453-63

16.BELLAVITE P, ANDRIOLI G, GUZZO P ET AL, Anal Biochem, 216, 1994, p. 444-50

17.UEMITSU N, NAKAYOSHI H. Toxicol Appl Pharmacol., 75(1), 1984, p. 1-7.

18.SUZUKI K, NAKAGAWA K, YAMAMOTO T, MIYAZAWA T, KIMURA F, KAMEI M, MIYAZAWA T., Biosci Biotechnol Biochem. 79(10), 2015, p. 1669-75.

19.BUZEA C.G., MIRESTEAN C.C., AGOP M., PAUN V.P., IANCU D.T. U.P.B. Sci. Bull., Series A, 2019, Vol. 81, Iss. 2, p. 265-278

20.D SCHOLTEN1, J TREBICKA2, C LIEDTKE1 AND R WEISKIRCHEN, Laboratory Animals, Vol. 49(S1), 2015, p. 4-11

21.TATARCIUC, D, VASINCU, D, STOLERIU, G, IANCU, RI, COSTULEANU, M, Rev. Chim., 69(5), 2018, p. 1187-1190

22.SMITH L, B. INGERMAN CM, SILVER MI: I LabClin Med 88, 1976, p. 167-172

23.VASINCU, D, IANCU, RI, CAZAN, I, STOLERIU, G, COSTULEANU, M, Rev. Chim., 69(7), 2018, 1817 1820

$\overline{\text { Manuscript received: } 12.12 .2019}$ 